The relationship between short-term memory and listening

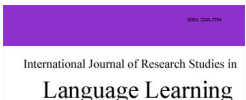
comprehension ability of IELTS test takers at different language proficiency levels

Mahdavi Zafarghandi, Amir

University of Guilan, Iran (amahdavi@guilan.ac.ir)

Bahrpeyma, Mitra $\$

University of Guilan, Iran (Mitra bahrpeyma@yahoo.com)

Language Learning

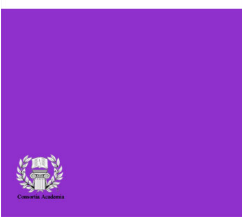

ISSN: 2243-7754 Online ISSN: 2243-7762

OPEN ACCESS

Received: 9 February 2016

Revised: 15 March 2016 DOI: $10.5861 / \mathrm{ijrs} 11.2016 .1441$

\title{
Abstract
}

The present study aimed at investigating the relationship between Short Term Memory and Listening Comprehension ability of the IELTS test takers at three levels of language proficiency. According to scholars like Revlin (2013) and Cowan (2008), Short Term Memory is a part of human mind that can hold a limited amount of information for immediate use. The Short Term Memory span of the participants of this study was measured through Short Term Memory Span test, their proficiency level was estimated by Oxford Placement Test. Finally, a listening section of the IELTS test was carried out. Findings of this study suggest that, for the advanced level IELTS test takers, Short Term Memory plays a significant intervening role. The implication of the results recommends that working on the memory of test takers and increasing the capacity of their Short Term Memory is needed in preparing advanced level students to take IELTS exam.

Keywords: memory; short term memory; IELTS listening; proficiency level; listening comprehension 


\section{The relationship between short-term memory and listening comprehension ability of IELTS test takers at different language proficiency levels}

\section{Introduction}

Each year many people all over the world take IELTS exam for different purposes like emigration or studying abroad. For them the final results of this exam could be so important that one of the main concerns of them would be the validity of their scores. Recent researches have revealed that IELTS exam correlates positively with multiple intelligence and background knowledge (Bagherkazemi, 2008; Malaee, 2010; Moaven, 2008). In my own experience as a second language learner who took an international English language exam like IELTS twice, I found some tasks of different skills really difficult to accomplish, especially listening comprehension ones, although those were not very hard exercises regarding their level of proficiency. After reading about the cognitive burden of language related tasks I realized that I am not alone in this. Ohata (2006, p. 21) in the introduction to his article says "as my experience as a L2 learner certainly tells, many kinds of cognitive tasks in the L2, such as remembering numbers or dates in listening comprehension [...], seem to require more mental energy and time than in the L1". Furthermore, Cook (2008, p. 124) believes that L2 learners have 'cognitive deficits', which means that they have difficulties in processing procedures in the second language. To show this he examined advanced level students and concluded that L2 learners have problems understanding the text even when they know all the grammar and vocabulary.

One aspect of the human's mind is Short Term Memory, where short-term storage of information happens, and has always been a matter of concern to many scholars. In a very early study, Glicksberg (1963, cited in Cook, 1997) measured the STM of L2 learners through digit span and showed that their L2 memory span have a 0.8 digits deficit compared to their L1 memory span scores. In another study, in an attempt to show the limitedness of Short Term memory span in second language, Cook (1997, p. 283) "contrasted the average span of 5.9 digits for adult beginners in English with the 6.7 of advanced learners". In addition, according to Brown and Hulme (1992) Short Term memory span is the number of material that can be rehearsed in a definite duration of time, and because languages vary in the speed of articulation, Short Term memory capacity alter in different languages (although this is not the only cause). In their article, Brown and Hulmer (1992, p. 110) claim that Short Term Memory Span "for any type of material in a second and less familiar language will be reduced". Brown and Hulme (1992, p. 117) argued that Phonological Short Term Memory is significant in "the processing of fluent language and in acquisition of both a first and second language".

Ohata (2006) verifies the effect of the speed of utterance on the listening comprehension ability of an L2 language learner and says the increasing processing load of an L2 utterance makes it more difficult to understand, and even though a L2 learner may recognize all the words as they are spoken, he or she cannot retain the whole pieces of utterance long enough to interpret. Therefore, he claims that memory "can play a significant role in L2 listening comprehension processes" (Ohata, 2006, p. 22). Finally, based on some different researches done in the area of short-term and working memory and learning, there is a correlation between the students' working memory and their proficiency and achievement at key levels of education (Baddeley, 1992; Gathercole \& Alloway, 2004). Indeed memory plays a significant role in all kinds of learning in general and in language learning in particular, and although its role in learning and comprehension has been investigated by many scholars, there is still room for delving more deeply into the relationship between Short Term memory and listening comprehension ability.

\subsection{Statement of the Problem}

As stated earlier, the results of the IELTS exam can play a major role in future of its takers, and based on the studies mentioned above, it has been shown that there are some intervening factors in the final results of this 
The relationship between short-term memory and listening comprehension ability of IELTS test takers

exam. In addition, because of the role of memory in learning and comprehension it is assumed that Short Term Memory may affect the performance of test takers at different levels of proficiency. Therefore, in an attempt to examine the truthfulness of this hypothesis, this study enquired into the relationship between Short Term Memory and ILETS listening comprehension ability of test takers with lower intermediate, upper intermediate and advanced level of language proficiency.

Regarding the aims of this study, the following research questions will be sought:

$>\quad$ What is the relationship between Short Term memory and Listening Comprehension ability of IELTS test takers with different language proficiency levels?

$>\quad$ Do the three groups of test takers differ in their strengths of correlation between Short Term memory and Listening Comprehension ability of IELTS test?

And the research hypothesis (null hypothesis) is:

$>\quad$ There is no significant relationship between Short Term Memory and IELTS listening comprehension ability of test takers at each language proficiency level.

\section{Literature Review}

\subsection{Short-Term, Working and Auditory Working Memory}

Revlin (2013) defines Short Term Memory as a reflection of our conscious awareness. Cowan (2008, para. 7) based his definition of short term memory on the work of Atkinson and Shiffrin (1968, cited in Cowan, 2008) and noted that it "reflect(s) faculties of the human mind that can hold a limited amount of information in a very accessible state temporarily." To expand the meaning of the Short Term Memory (STM) we need to consider its main properties including the capacity of STM, the amount of time the information lasts in it and the answer to the question, "why do we forget facts held in STM?"

Atkinson and Shiffrin (1968, cited in Revlin 2013) propose that the capacity of Short-term memory is seven items of information (give or take two). Miller (1956) says it is seven "chunks" - implied as an integrated piece of information. "A typical adult's memory span is approximately 7 (between 5 and 9) unrelated items" (Miller, 1956, cited in Revlin, 2013, p. 120). The information lasts very shortly in Short-term memory. For unrehearsed data this duration is between 15 to 30 seconds (Revlin, 2013; Carroll, 2007). Finally, as noted by Duong (2006), Information Loss is unavoidable. There are three main theories as to why we forget from our STM: Displacement during which existing information is replaced by new information when the capacity of STM is full; Decay which means that information lasts very shortly in STM; and Interference in which other data in STM can distort the main information.

In addition to the notion of STM some scholars introduced another term called Working Memory. According to Cowan (2008), after the revelation of Baddeley and Hitch's model in 1986, this term became dominant in the field of Psycholinguistics. The working memory model proposed by Baddeley and Hitch has three key characteristics which differentiate it from the Atkinson-Shiffrin model of short-term memory. Cowan (2008, para. 8) mentions that in the Baddeley and Hitch's model "verbal-phonological and visual-spatial representations were held separately, and were managed and manipulated with the help of attention-related processes, termed the central executive".

Heyman (2012) defined auditory working memory as one part of working memory system. As mentioned earlier, one part is the visual-spatial sketchpad and the other is the verbal loop, often called the phonological loop. In her definition it is the latter that is usually called AWM. Heyman (2012) continued that when information comes into our auditory system, we must actively rehearse what we have heard because this information rapidly 
Mahdavi Zafarghandi, A., \& Bahrpeyma, M.

decays after one or two seconds. In order to repeat the information to ourselves, we must use selective attention, screening out irrelevant sounds to attend to the significant information at hand. According to Heyman (2012) research has shown that if short term memory is low, we have a hard time selecting what we wish to hear. In other words, selective attention doesn't work so well when AWM is low.

\subsection{Listening comprehension}

Although listening comprehension skill was neglected for many years within applied linguistics, its importance has been found by the work of many scholars who emphasized the role of comprehension and comprehensible input in triggering language development. According to Flowerdew and Miller (2005) for many years listening comprehension was seen as the mastery of some sub skills like discriminating sounds in a word and deducing the meaning of unfamiliar words which form the focus of teaching and testing. But, during 1980's and 1990's applied linguistics began to "borrow new theoretical models of comprehension from the field of cognitive psychology" (Flowerdew \& Miller, 2005, p. ix). The distinction between top-down and bottom-up processing, viewing learners as active ones who can make their own meanings, the role of background knowledge and schemata in comprehension, conversation analysis and discourse analysis are all the important notions that were derived from cognitive psychology and found their way to the field of listening comprehension.

According to Flowerdew and Miller (2005, p. 22) "We learn our mother tongue, as children, by listening to it. Then, throughout our lives, listening takes up a substantial proportion of our communication time." To illustrate the way by which we attend the message in our mother tongue, a model has been developed by Bourne, Dominowski, and Coftus (1979, cited in Flowerdew \& Miller, 2005). The model is called the Human Information-Processing System and explains how we acquire, retain, and retrieve information.

\subsection{Listening comprehension and STM}

As mentioned by Ohata (2006) in the study of Glicksberg (1963), which was one of the earlier studies in this field and was designed to investigate the relationship between short-term memory span and language proficiency, he found that the span of short-term memory is reduced in a second language. In a similar study, Loe (1964, cited in Ohata, 2006) investigated L2 memory span for lengthy and grammatically complex sentences and found that "longer sentences were more difficult to recall than shorter ones, and also that there were considerable qualitative differences in the ways of recalling grammatically complex sentences between proficient students (including native speakers and advanced students) and less proficient students" (Ohata, 2006, p. 25). Additionally, as declared by Ohata (2006), according to recent research adult L2 learners' ability in processing complex L2 structures will increase while their capacity for language processing develops.

Apart from the studies on the relationship between STM and listening comprehension, some research focuses on the relation between working-memory and listening comprehension. In a very recent one, Satori (2012) investigated the role of working memory in L2 listening comprehension. The results suggest that "limited capacity of WM may affect L2 listening comprehension when L2 linguistic knowledge and processing skills are not efficient enough" (Satori, 2012, p. 9). This means that "Beginner-level listeners need to devote more cognitive resources to process what they hear in each phase of listening. Therefore, WM capacity related to attention control and processing efficiency possibly affects the L2 performance of the lower-level listeners" (Satori, 2012, p. 9).

\section{Methodology}

This research attempts to seek the relationship between Short-Term Memory and listening comprehension ability of IELTS test takers at different language proficiency levels. In order to find specific answers to the research questions the following method was applied: 
3.1 Design

With regard to research questions, the design of this study is 'EX Post Facto design' because of the nature of correlational analysis. Also, to serve its purpose, this study followed a quantitative research design. The research variables are:

$>$ Independent variables: Short term memory span, listening span

$>$ Dependent variables: measure of IELTS listening comprehension

$>\quad$ Moderator variables: the proficiency level (intermediate or advanced)

\subsection{Participants}

The study involved 145 participants, including 44 males and 101 females, aged 18-34. The average of the age of the group was 22. The participants were a mixture of undergraduate and graduate students of the "English Literature", "Translation" and "Teaching English as a second or foreign language" fields of study, with 112 undergraduate and 33 graduate students. As all the participants were selected from the three mentioned fields of study (most of them were students of University of Guilan, with some graduates of Azad University) they were all familiar with English as a second language, with all except one case have Farsi as their mother tongue. 20 of the participants took part voluntarily, but the most were university students whose class time was assigned to this study under the permission of their professor.

\subsection{Materials}

Memory span tests - The first testing tool was Digit span test with two versions: L1 and L2 random digit test. According to a Wikipedia article, Digit Span Task is "used to measure working memory's number storage capacity. Participants are presented with a series of digits (e.g., '8, 2, 4') and must immediately repeat them back. If they do this successfully, they are given a longer list (e.g., '9, 2, 4, 1'). The length of the longest list a person can remember is that person's digit span" (Wikipedia). For this study, strings up to 10 digits length were used both in L1 and L2 versions. For each digit length two strings were shown to candidates for 10 seconds and after the string disappeared from the screen, participants would write them down in blank space in the answer sheet. Two opportunities for one digit length were given to check for reliability.

Listening span test or auditory memory span test - In terms of measuring the listening span one procedure is reading out loud a series of digits by the examiner and asking the participants to write what they heard in the same order. For this case a series of digits was retrieved from a related website and used in the procedure.

Proficiency test - Proficiency level of the test takers is one of the main variables in this study, so it was measured through "quick placement test" of "Oxford University Press and University of Cambridge Local Examinations Syndicate" version 2. The test contains 60 questions of multiple choice and cloze format.

IELTS listening comprehension test - An IELTS listening test was conducted in each session of study. The test was retrieved from the book "IELTS 7", one of the books from the series of Cambridge Books for Cambridge Exams. The first test of the book was utilized. The exams of the book are official examinations papers from University of Cambridge ESOL Examinations. IELTS listening comprehension test consists of four sections. According to IELTS organization website "A variety of voices and native-speaker accents are used and each section is heard only once" ("IELTS I Test Takers - Test format", 2014). The structure of four sections is as follows:

$>$ Section 1: A conversation between two people set in an everyday social context.

$>$ Section 2: A monologue set in an everyday social context (e.g. a speech about local facilities).

$>\quad$ Section 3: A conversation between up to four people set in an educational or training context, (e.g. a university tutor and a student discussing an assignment).

$>\quad$ Section 4: A monologue on an academic subject (e.g. a university lecture). 


\subsection{Procedure}

Each participant attended two testing sessions, one for measuring their proficiency level which lasted about 30 minutes and another one for doing the rest of the test which took about 55 to 60 minutes of their class session time. Firstly, to determine the language proficiency level of the participants, the proficiency test was administered to all of them. Based on the results of this test the whole population was separated in three groups, named lower intermediate, upper intermediate and advanced. Secondly, the memory span of the participants was measured by the use of 'Memory Span Test' and 'Listening Span Test'. Finally the IELTS listening test was conducted which took about 40 minutes in each session and was administered in a very similar way to the real IELTS test with the audio files from speakers being played and students have their test booklets and separated answer sheets to write down the answers in them.

After gathering the data, reliability of each instrument was checked. Cronbach's Alpha measurement was conducted to see whether the two memory span tests are a reliable measure of these variables. According to this reliability statistics, short term memory span tests show a Cronbach's alpha of .61, so it has a fair reliability index compared to the other measures used. The second instrument was the Listening Span Tests (or auditory memory span tests) for which the Cronbach's Alpha was calculated too and these tests showed very slight reliability (Cronbach' Alpha of .52). In order to calculate the reliability of placement test and IELTS listening test, Split-Half Reliability method was used. The final Pearson Product Moment Correlation and the Reliability of these two tests were calculated respectively as following: Placement test .73, .84; and IELTS listening Test .76, .86. Therefore, these two tests were counted as pretty reliable measures.

\section{Data Analysis and Results}

In order to find the answer of the research questions, multiple regression analyses were run through SPSS 18. First, the multiple regressions were done to find the answer to the question of whether or not there is a relationship between STM and IELTS listening comprehension scores in each language proficiency level group. In the second step, a more specific analysis of the correlations and the predictability of the dependent variable being affected by the independent variables were made.

\subsection{Investigating the first research question}

As mentioned earlier, participants' test scores were separated in three groups based on their proficiency level, so we could see that in which group (meaning lower intermediate, upper intermediate or advanced) IELTS listening score is more dependent on memory scores. Statistically speaking, based on the results of the placement test, $42.1 \%$ of the participants were at advanced level, $36.6 \%$ were at upper intermediate level and the remaining were at lower intermediate level of language proficiency.

\section{Table 1}

Frequencies and percent of participants' placement test score

\begin{tabular}{lccc}
\hline & $\mathrm{f}$ & $\mathrm{p}$ & $\mathrm{P}$ \\
\hline adv & 61 & 42.1 & 42.1 \\
Low-int & 31 & 21.4 & 63.4 \\
Up-int & 53 & 36.6 & 100.0 \\
Total & 145 & 100.0 & \\
\hline
\end{tabular}

Additionally, the outcomes of the memory tests show that $41.4 \%$ of the participants had the L2 memory span of 7, 30.3\% of them had the L2 memory span of 8 and $15.2 \%$ of the participants had the L2 memory span of 9 . In Auditory memory or listening span test, $43.4 \%$ of the participants had the span of $6,32.4 \%$ of them had the span of 7 and $13.8 \%$ of the participants showed the span of 5 . If we consider that there is no relationship between IELTS listening comprehension score of the participants and their memory span, the multiple correlation or multiple regression must be zero $(\mathrm{R}=0)$. To prove it right or wrong, after grouping the scores a regression 
The relationship between short-term memory and listening comprehension ability of IELTS test takers analysis was run for the three levels of participants.

Table 2

Frequencies and percent of participants' IELTS listening score

\begin{tabular}{lccc}
\hline & $f$ & $p$ & $P$ \\
\hline 2.50 & 4 & 2.8 & 2.8 \\
3.50 & 2 & 1.4 & 4.1 \\
4.00 & 7 & 4.8 & 9.0 \\
4.50 & 18 & 12.4 & 21.4 \\
5.00 & 11 & 7.6 & 29.0 \\
5.50 & 32 & 22.1 & 51.0 \\
6.00 & 19 & 13.1 & 64.1 \\
6.50 & 25 & 17.2 & 81.4 \\
7.00 & 15 & 10.3 & 91.7 \\
7.50 & 7 & 4.8 & 96.6 \\
8.00 & 4 & 2.8 & 99.3 \\
8.50 & 1 & .7 & 100.0 \\
Total & 145 & 100.0 & \\
\hline
\end{tabular}

First the calculation was done in the advanced group. The results are shown in the following table.

\section{Table 3}

Summary of the regression analysis at the advanced level

\begin{tabular}{cccc}
\hline $\mathrm{R}$ & $\mathrm{R}$ Square & Adjusted R Square & SE \\
\hline $.512^{\mathrm{a}}$ & .262 & .236 & .83568 \\
\hline Note. Predictors are L2 Listening Span Test Score \& L2 Memory Span Test Score.
\end{tabular}

As the data indicate, the common variance among L2 Listening (or Auditory) Span test scores, L2 Memory Span Test scores and IELTS listening comprehension test scores is .26 which means that $26.2 \%$ of IELTS listening score can be accounted for by L2 Listening Span and L2 memory span of test takers.

For the upper intermediate participants the results were as follows:

\section{Table 4}

Summary of regression analysis at the upper intermediate level

\begin{tabular}{cccc}
\hline $\mathrm{R}$ & $\mathrm{R}$ Square & Adjusted R Square & SE \\
\hline $.259^{\mathrm{a}}$ & .067 & .029 & .64916 \\
\hline
\end{tabular}

Note. Predictors are L2 Listening Span Test Score \& L2 Memory Span Test Score.

According to the table above, the common variance among L2 Listening (or Auditory) Span test scores, L2 Memory Span Test scores and IELTS listening comprehension test scores for upper intermediate participants is .06 which means that $6.7 \%$ of IELTS listening score can be accounted for by L2 Listening Span and L2 memory span of test takers.

The same analysis for lower intermediate participants revealed these results:

Table 5

Summary of regression analysis at the lower intermediate level

\begin{tabular}{cccc}
\hline $\mathrm{R}$ & $\mathrm{R}$ Square & Adjusted R Square & SE \\
\hline $.123^{\mathrm{a}}$ & .015 & -.058 & .90068
\end{tabular}

Note. Predictors are L2 Listening Span Score \& L2 Memory Span Test Score.

As indicated in the table, the common variance among L2 Listening (or Auditory) Span test scores, L2 Memory Span Test scores and IELTS listening comprehension test scores for lower intermediate participants is .015 which means that $1.5 \%$ of IELTS listening score can be accounted for by L2 Listening Span and L2 
Mahdavi Zafarghandi, A., \& Bahrpeyma, M.

memory span of test takers.

\subsection{Investigating the second research question}

The second research question aims at examining the strength of predictability of each independent variable in anticipating the dependent variable. In other words, it intends to see how well each of the memory span factors correlates with IELTS listening score at every language proficiency level. The following table shows the correlation coefficients for the advanced level scores.

\section{Table 6}

Coefficients of advanced level estimated with regression analysis

\begin{tabular}{|c|c|c|c|c|c|c|c|}
\hline \multirow{3}{*}{ Model } & \multirow{2}{*}{\multicolumn{2}{|c|}{$\begin{array}{c}\text { Unstandardized } \\
\text { Coefficients }\end{array}$}} & \multirow{3}{*}{$\begin{array}{c}\begin{array}{c}\text { Standardized } \\
\text { Coefficients }\end{array} \\
\text { Beta }\end{array}$} & \multirow{3}{*}{$\mathrm{t}$} & \multirow{3}{*}{ Sig. } & \multicolumn{2}{|c|}{ Correlations } \\
\hline & & & & & & & \\
\hline & $\mathrm{B}$ & $\mathrm{SE}$ & & & & $\operatorname{Pr}$ & Part \\
\hline (Constant) & 5.824 & 1.087 & & 5.358 & .000 & & \\
\hline L2 Memory Span Test Score & -.368 & .128 & -.353 & -2.872 & .006 & -.358 & -.330 \\
\hline L2 Listening Span Test Score & .567 & .134 & .519 & 4.216 & .000 & .491 & .484 \\
\hline
\end{tabular}

As the table indicates, the statistical significance of this regression analysis is $.000(\mathrm{p}<.05)$ which means that this regression statistically significantly predicts the IELTS listening score. The standardized equation of IELTS listening score can be written down as:

IELTS Listening score =- 0.353 (L2 memory span) + 0.519 (L2 listening span)

As this equation shows, considering a combination of parameters, the coefficient of L2 memory span is negative, so when L2 memory span score increases, the IELTS listening score decreases. But, IELTS listening score is predicted to increase 0.519 when L2 Listening Span goes up by one. The same equation can be written for upper intermediate based on the data illustrated in the following table:

\section{Table 7}

Coefficients of upper intermediate level estimated with regression analysis

\begin{tabular}{|c|c|c|c|c|c|c|c|}
\hline \multirow[t]{2}{*}{ Model } & \multicolumn{2}{|c|}{$\begin{array}{l}\text { Unstandardized } \\
\text { Coefficients }\end{array}$} & \multirow{2}{*}{$\begin{array}{c}\begin{array}{c}\text { Standardized } \\
\text { Coefficients }\end{array} \\
\text { Beta }\end{array}$} & \multirow[t]{2}{*}{$\mathrm{t}$} & \multirow[t]{2}{*}{ Sig. } & \multicolumn{2}{|c|}{ Correlations } \\
\hline & $\mathrm{B}$ & SE & & & & $\mathrm{pr}$ & Part \\
\hline (Constant) & 3.923 & .963 & & 4.072 & .000 & & \\
\hline L2 Memory Span Test Score & .093 & .099 & .131 & .935 & .354 & .132 & .129 \\
\hline L2 Listening Span Test Score & .170 & .119 & .200 & 1.428 & .160 & .200 & .197 \\
\hline
\end{tabular}

Based on this table, the standardized predictive equation is:

IELTS Listening score $=0.131$ (L2 memory span $)+0.200$ (L2 listening span $)$

Therefore, in this equation both variables are weak predictors of IELTS listening. Taking another look at the level of significance, L2 memory span and L2 listening span tests are correlated with the IELTS listening score at levels upper that .05 which means that their correlation is not significant. And for the lower intermediate level the results were as follows: 
The relationship between short-term memory and listening comprehension ability of IELTS test takers

Table 8

Coefficients of lower intermediate level estimated with regression analysis

\begin{tabular}{|c|c|c|c|c|c|c|c|}
\hline \multirow[t]{2}{*}{ Model } & \multicolumn{2}{|c|}{$\begin{array}{c}\text { Unstandardized } \\
\text { Coefficients }\end{array}$} & \multirow{2}{*}{$\begin{array}{c}\begin{array}{c}\text { Standardized } \\
\text { Coefficients }\end{array} \\
\text { Beta }\end{array}$} & \multirow[t]{2}{*}{$\mathrm{t}$} & \multirow[t]{2}{*}{ Sig. } & \multicolumn{2}{|c|}{ Correlations } \\
\hline & $\mathrm{B}$ & $\mathrm{SE}$ & & & & $\mathrm{pr}$ & Part \\
\hline (Constant) & 3.776 & 1.571 & & 2.404 & .023 & & \\
\hline L2 Memory Span Test Score & -.034 & .206 & -.033 & -.163 & .872 & -.031 & -.031 \\
\hline L2 Listening Span Score & .132 & .204 & .131 & .644 & .525 & .123 & .123 \\
\hline
\end{tabular}

Note. Dependent Variable is IELTS Listening Score.

According to this table, with taking significant level into consideration, at the level of lower intermediate, the correlation coefficients of L2 Memory Span and L2 Listening Span are not significant in predicting the IELTS listening score.

\section{Discussion and Conclusion}

According to British Council website, IELTS is an example of Proficiency test. As addressed in their website, "A proficiency test measures a learner's level of language". And "Proficiency tests are very frequent as the end aim (and motivation) of language learning" ('proficiency-test', 2008). So in an ideal situation no variable other than the knowledge of language must intervene in the process of testing proficiency level. However, the findings of this study showed that at the advanced level, the correlation between listening span of the IELTS test takers and their listening comprehension ability is significant and Short Term Memory can influence the performance on their listening comprehension part of IELTS test. Moreover, based on the results of this study, the lower the proficiency level, the lesser the strength of the correlation between Short Term Memory and IELTS listening comprehension.

These findings are in agreement with the findings of Loe (1964, cited in Ohata, 2006) who investigated the L2 memory span for lengthy and grammatically difficult sentences and declared that proficient students differ qualitatively with less proficient students in the ways of recall. In this study it is shown that the lower the proficiency level, the lesser the strength of the correlation between Short Term Memory and IELTS listening comprehension.

According to the outcomes of the related correlational analysis of this study, only the correlation coefficients at the advanced level were significant in predicting the IELTS listening comprehension score. At intermediate levels, these coefficients were not meaningful based on their level of significance and could be ignored in final conclusions. However, at the advanced level, both parameters were considerable. In addition, the results showed that, at the advanced level, when L2 memory span score increases, the IELTS listening score decreases, but IELTS listening score is predicted to increase 0.519 when L2 Listening Span goes up by one.

Although the findings of this study are consistent with the findings of some previous researches mentioned by Ohata (2006), they are in conflict with the findings of Satori (2012). One explanation for this discrepancy may lie in the fact that the process of measuring Working Memory is different from Short Term Memory. During the procedure of measuring the working memory, one can consider separate parts of it and how much each part involves in doing a task. But in the process of measuring Short Term Memory, memory would be considered as one whole element with a special capacity that can or cannot play a role in completing a special task.

In addition to above mentioned discussion, by taking a look at the definitions given by Farhady et al. (2012) and Flucher (2010) a test will be considered as invalid if it does not measure what it is supposed to measure. In other words, if in a test like IELTS where the final aim is measuring proficiency level of test takers, we could find other factors which intervene in the final results, then it could be said that the validity of the test is threatened.

Based on the results of this study, only for the advanced level test takers the correlation between IELTS 
Mahdavi Zafarghandi, A., \& Bahrpeyma, M.

listening comprehension test score and L2 listening span test was significant. In addition, although the correlation was significant, the coefficient was not very strong. So, it can be concluded that the correlational relation between these two factors, although not negligible, is too slight to be considered as a threatening factor to the validity of IELTS listening comprehension test.

In the end, it is worth mentioning that because of the nature of correlational analysis, the results do not imply a cause and effect relationship, and the low correlations between the independent and dependent variables hinder the generalization of the results. However, the role of the Short Term Memory, although being slight, cannot be neglected. The aim of this study was to make teachers and test designers aware of other factors that may intervene in the process of doing listening comprehension part of the IELTS exam. Therefore, language teachers, especially, must take the factor of short term memory into consideration and help their students improve their memory spans by doing some memory exercises and by learning different strategies before taking the IELTS test.

\section{References}

Baddeley, A. (1992). Working memory. Science, 255(5044), 556-559. http://dx.doi.org/10.1126/science.1736359

Bagherkazemi, M. (2008). The relationship between test takers multiple intelligences and their performance on the reading sections of TOEFL and IELTS. Unpublished master's thesis for master's degree, Allameh Tabatabaee University, Tehran, Iran.

Brown, G. D.A., \& Hulme, C. (1992). Cognitive processing and second language processing: The role of short term memory. In R. J. Harris (Ed.), Cognitive processing in bilinguals (pp. 105-121). Elsevier. http://dx.doi.org/10.1016/S0166-4115(08)61490-9

Carroll, D. W. (2007). Psychology of language. Tehran: Rahnama.

Cambridge IELTS 7. (n.d.). Retrieved from

http://www.cambridge.org/us/cambridgeenglish/catalog/cambridge-english-exams-ielts/cambridge-ielts7

Cook, V. (2008). Second language learning and language teaching (4th ed.). London: Arnold.

Cook, V. (1997). The consequences of bilingualism for cognitive processing. In A. de Groot, \& J.F. Kroll (Eds.), Tutorials in bilingualism: Psycholinguistic perspectives (pp. 279-300). Lawrence Erlbaum.

Cowan, N. (2008). What are the differences between long-term, short-term, and working memory? Retrieved from http://www.ncbi.nlm.nih.gov/

Duong, T. T. (2006). How to improve short-term memory in interpreting. Unpublished Masteral thesis, Hanoi University of foreign studies.

Farhady, H., Ja'farpur, A., \& Birjandi, P. (2012). Testing language skills from theory to practice. Tehran: SAMT.

Flowerdew, J., \& Miller, L. (2005). Second language listening: Theory and practice. Cambridge: Cambridge University Press. http://dx.doi.org/10.1017/CBO9780511667244

Fulcher, G. (2010). Practical language testing. London: Hodder Education.

Gathercole, S., \& Alloway, T. (2004). Working memory and classroom learning. Journal of Professional Association for Teachers of Students with Specific Learning Difficulties. Retrieved from http://www.psychology.dur.ac.uk/research/wm/index.htm

Heyman, N. (2012, July 9). Auditory memory: In one ear and out of the other? Speech therapist talking talk RSS. Retrieved from http://nikkiheyman.co.za/auditory-memory-in-one-ear-and-out-of-the-other

Malaee, N. (2010). The effect of familiarity with academic topics on learners' reading proficiency as measured by IELTS. Unpublished Masteral thesis for master's degree, University of Guilan, Rasht, Iran.

Memory span. (n.d). Wikipedia. Retrieved from http://en.wikipedia.org/wiki/Memory_span

Moaven, B. (2008). The relationship between learners' critical thinking ability and their performance in the reading sections of the TOFEL and IELTS Tests. Unpublished Masteral thesis, Ferdowsi University, Mashhad, Iran.

Ohata, K. (2006). Auditory short-term memory in L2 listening comprehension processes. Journal of Language 
The relationship between short-term memory and listening comprehension ability of IELTS test takers

and Learning, 5(1), 21-28.

Proficiency test. (2008). Retrieved from https://www.teachingenglish.org.uk/article/proficiency-test

Revlin, R. (2013). Cognition: theory and practice. Macmillan Education.

Satori, M. (2012). The role of working memory in L2 listening comprehension. Proceedings of the 17th

Conference of Pan-Pacific Association of Applied Linguistics (pp. 8-9).

Welcome to IELTS. (n.d.). IELTS. Retrieved from

https://www.ielts.org/test takers_information/what_is_ielts.aspx

Welcome to IELTS. (n.d.). IELTS. Retrieved from

http://www.ielts.org/test_takers_information/what_is_ielts/test_format.aspx 
Mahdavi Zafarghandi, A., \& Bahrpeyma, M. 